DOI: 10.4274/tpa.45.329

\title{
Erken doğmuş bebeklerde klinik olarak anlamlı patent duktus arteriyozus tedavisinde oral ibuprofenin etkinliği
}

\author{
The efficacy of oral ibuprofen in the treatment of clinically \\ significant patent ductus arteriosus in preterm infants
}

\author{
Müjgan Arslan, Özgür Olukman, Şebnem Çalkavur, Füsun Atlıhan, Timur Meşe, İsmail Cengiz Öztürk, \\ Dr. Behçet Uz Çocuk Hastalıkları ve Cerrahisi Eğitim ve Araştırma Hastanesi, İzmir, Türkiye
}

\section{Özet}

Amaç: Çalışmamızda, hastanemizde izlenen erken doğmuş bebeklerde patent duktus arteriyozus (PDA) sıklığının, kendiliğinden kapanma oranlarının, kapanmayanlarda ağızdan ibuprofen tedavisinin etkinliğinin ve yan etkilerinin araştıııması amaçlandı.

Gereç ve Yöntem: Eylül 2007-Ocak 2009 arasında 623 erken doğmuş bebek, doğumdan sonra 24-48 saat içinde ekokardiyografiyle (EKO) değerlendirildi. Hemodinamik olarak anlamlı PDA saptanıp kendiliğinden kapanma gerçekleşmeyen hastalara ağızdan ibuprofen ilk gün 10 $\mathrm{mg} / \mathrm{kg} / \mathrm{gün}$, ikinci ve üçüncü günler $5 \mathrm{mg} / \mathrm{kg} / \mathrm{gün} 24$ saat arayla verildi. Duktusu kapanmayan hastalara ikinci kez tedavi uygulandı. Yanıt alınamayanlarda cerrahi ligasyona gidildi.

Bulgular: Altı yüz yirmi üç hastanın 100'ünde PDA saptandı (\%16). Patent duktus arteriyozus saptanan hastalarda kendiliğinden kapanma oranı \%61 idi. Kapanma olmayan ve hemodinamik olarak anlamlı PDA'sı olan 39 hastanın \%95'inde ağızdan ibuprofenle kapanma sağlanırken, \%5'ine cerrahi uygulandı. Tedaviye bağlı önemli yan etki kaydedilmedi. Gebelik haftası, doğum ağılığı arttıkça kendiliğinden kapanma arttı. Duktus çapı, sol atriyum/aort kökü oranı arttıkça kendiliğinden kapanma azaldı.

Çıkarımlar: Ağızdan ibuprofenin yüksek etkinliği kabul edilebilir yan etkileri, ve düşük maliyeti nedeniyle duktusun kapatılmasında güvenle kullanılabilecek bir tedavi olduğu düşüncesindeyiz. (Türk Ped Arş 2010; 45: 329-33)

Anahtar sözcükler: Bebek, duktus arteriyozus, erken doğmuş bebek, ibuprofen

\section{Summary}

Aim: This study was designed to investigate the incidence of patent ductus arteriosus (PDA) by echocardiographic examination, to determine spontaneous closure rates, to investigate the efficacy of oral ibuprofen in the treatment of hemodynamically significant PDA and to define potential drug side effects in preterm infants followed at the neonatology department of İzmir Dr. Behçet Uz Children's Hospital.

Material and Method: Between September 2007-January 2009, 623 preterm infants were evaluated by echocardiography within first 24-48 postnatal hours. Oral ibuprofen treatment was administered to patients with clinically and hemodynamically significant PDA at 10 $\mathrm{mg} / \mathrm{kg} /$ day initial dose, and following second and third doses of $5 \mathrm{mg} / \mathrm{kg} /$ day with 24 hours intervals. A second course of ibuprofen was given to patients whose was not closed PDA after the first course. Patients who didn't respond to the second course underwent surgical ligation.

Results: One hundred out of 623 patients were diagnosed as PDA (\%16). Spontaneous closure rate was $61 \%$. In ninetyfive percent of remaining 39 patients PDA was closed after oral ibuprofen administration. Five percent had to undergo surgical ligation. We didn't observe any considerable side effects. As the gestational week and the birthweight increased, spontaneous closure rate increased. On the other hand as the ductal size and the ratio of left atrium to aortic root increased spontaneous closure rate decreased.

Conclusions: Data suggest that oral ibuprofen may be a safe, effective and low cost treatment choice in closing PDA because of its reasonable side effects and practical applicability. (Turk Arch Ped 2010; 45: 329-33)

Key words: Ductus arteriosus, ibuprofen, infant, premature 


\section{Giriş}

Patent duktus arteriyozus (PDA), erken doğmuş yenidoğanlarda sıklıkla karşılaşılan, ventrikül içi kanama (VIK), nekrotizan enterokolit (NEK), kronik akciğer hastalığı $(\mathrm{KAH})$ risklerinin artışına yol açarak hastalık ve ölüm oranı üzerine olumsuz katkıları olan bir kalp anomalisidir (1-3). Bu bebeklerde duktusun farmakolojik veya cerrahi yolla kapatılmasının hastalık ve ölüm oranını önemli ölçüde azalttığı bilinmektedir. Tıbbi tedavide kullanılan siklooksijenaz inhibitörleri, prostaglandin E2'nin (PGE2) sentezini engelleyerek etki gösterirler. Bunlardan birisi olan indometazin, etkinliği kanıtlanmış ancak böbrek, sindirim sistemi ve beyin perfüzyonunda yaptığı değişikliklere bağı yan etkileri fazla olan bir ilaçtır $(4,5)$. Bu nedenle son yıllarda başka tedavi yöntemleri araştırılmış ve ibuprofen kullanımı (ağızdan veya damardan) gündeme gelmiştir (6). Yapılan pek çok çalışmada ibuprofenin gerek PDA'nın tıbbi tedavisinde, gerekse de koruyucu tedavisinde en az indometazin kadar etkili olduğu gösterilmiştir $(3,5,6)$. Üstelik bazı çalışmalarda ibuprofenin daha az beyin, böbrek ve mezenterik yan etkisinin olduğu, beyin kan akımının otoregülasyonunu arttırdığı ve nörolojik işlevleri koruduğu gösterilmiştir $(7,8)$. Ülkemizde damardan ibuprofen zor bulunan ve pahalı bir üründür. Ağızdan kullanılan ibuprofen ise düşük maliyetli, kolay uygulanabilen ve yeni çalışmalarda etkili bulunmuş bir ilaçtır.

Bu bilgiler ışığında yürüttüğümüz bu çalışmada, Hastanemiz Yenidoğan Servisi'nde izlenen erken doğmuş bebeklerde ekokardiyografi (EKO) incelemesi ile PDA sıkığını araştırmak, PDA saptananlarda kendiliğinden kapanma oranını belirlemek, kapanmayan, hemodinamik ve klinik açıdan anlamlı duktusu olanlarda ağızdan ibuprofen tedavisinin kapanma üzerine etkinliğini ve olası ilaç yan etkilerini saptamak amaçlanmıştır.

\section{Gereç ve Yöntem}

Dr. Behçet Uz Çocuk Hastalıkları ve Cerrahisi Eğitim ve Araştırma Hastanesi Yenidoğan Servisi'ne Eylül 2007Ocak 2009 tarihleri arasında yatıılan, gestasyon yaşı 37 haftanın altında olan 623 erken doğmuş bebek çalışmaya dahil edildi. Bu hastalarda doğum sonrası 24-48 saat içinde yapılan EKO incelemesi ile PDA araştıııldı. Patent duktus arteriyozus tespit edilen bebeklerde günlük EKO inceleme ile duktusun genişliği, soldan sağa şantın oranı ve kendiliğinden kapanma oranı izlendi. Doğuştan ölümcül malformasyon ya da doğuştan kalp hastalığına eşlik eden PDA olguları çalışmaya alınmadı.

Hemodinamik olarak anlamlı PDA tanısı için LA/Ao oranı (sol atriyum/aort kökü) $\geq 1,4$ veya duktus çapı $\geq 1,4$ $\mathrm{mm} / \mathrm{kg}$ olması ölçütleri arandı. Klinik olarak anlamlı PDA tanısı içinse üfürüm, hiperaktif prekordiyum, hipotansiyon, solunumda bozulma, takipne ve apne varlığı sorgulandı. Patent duktus arteriyozus saptanan hastalarda kendiliğinden kapanma için 48 saat beklenildi ve tıbbi tedavi olarak yalnızca sıvı kısıtlaması uygulandı. Ancak doğum sonrası 48 saatini doldurmasına rağmen önemli sol-sağ şant nedeniyle hemodinamik ve klinik olarak anlamlı duktusu devam eden hastalardan trombositopeni, böbrek yetersizliği, ViK, NEK, sepsis, kanama diyatezi, elektrolit dengesizliği ve ciddi indirekt hiperbilirübinemisi olmayanlara $10 \mathrm{mg} / \mathrm{kg} / \mathrm{gün}$ dozda ağızdan ibuprofen verildi. İlk dozu takiben 24 saat arayla ikinci ve üçüncü dozlar $5 \mathrm{mg} / \mathrm{kg} / \mathrm{doz}$ şeklinde uygulandı. Hastalar olası böbrek, sindirim sistemi ve beyne alabilecek yan etkileri açısından izlendi. Serum BUN, kreatinin, sodyum düzeyleri ve trombosit sayıları günlük olarak tedavi öncesi ve sonrası değerleriyle incelendi. Tedavi öncesi ve sonrası yapılan kraniyal ultrasonografi (USG) bulguları karşılaştırıldı. Tedavi alanlarda üçüncü günün sonunda EKO incelemesi tekrarlandı. Duktusu kapanmayan hastalara ikinci kez tedavi verildi. İkinci tedaviyle de yanıt alınamayan hastalara cerrahi kapatma tedavisi uygulandı. Ekokardiyografik incelemeler VIVID 3 (General Electric) cihazı ile yapıldı. İstatistik işlemleri için SPSS 15,0 paket programı kullanıldı. Tüm testlerde $p<0,05$ değerleri istatistiksel olarak anlamlı kabul edildi.

\section{Bulgular}

Çalışmaya alınan 623 erken doğmuş bebeğin 100'ünde (\%16) PDA saptandı. Yüz olgunun 54'ü erkek (\%54), 46’sı kız (\%46), ortalama gebelik yaşı $30,9 \pm 3,2$ hafta ve doğum ağırlı̆ı $1582,9 \pm 632,1$ gr'dı. Patent duktus arteriyozus saptanan hastaların özellikleri Tablo 1'de verilmiştir.

İzlemde 100 hastanın 61'inde kendiliğinden kapanma gerçekleşti (\%61). Hemodinamik ve klinik olarak anlamlı PDA 39 hastada vardı (\%39). Anlamlı PDA nedeniyle tedavi gerektiren bu 39 hastanın \%82'sinde birinci, \%13'ünde ise ikinci ibuprofen tedavisi sonrasında olmak üzere toplam \%95'inde tıbbi tedavi ile kapanma gözlendi. Tıbbi tedaviye hiç yanıt alınamayan \%5 hastada cerrahi "ligasyona" gidildi.

\begin{tabular}{|l|c|}
\hline \multicolumn{2}{|l|}{ Tablo 1. PDA saptanan $\mathbf{1 0 0}$ hastanın özellikleri } \\
\hline Gestasyon yaşı ortalaması & $30,9 \pm 3,2$ hafta \\
\hline Doğum ağırlığı ortalaması & $1582,9 \pm 632,1 \mathrm{gr}$ \\
\hline Cinsiyet & $\% 54$ Erkek \%46 Kız \\
\hline Ortalama duktus çapı & $1,51 \pm 0,83 \mathrm{~mm} / \mathrm{kg}$ \\
\hline Ortalama LA/Ao oranı & $1,43 \pm 0,29 \mathrm{~mm}$ \\
\hline Mekanik ventilasyon tedavisi & $\% 41$ \\
\hline Sıkıntıı solunum sendromu & $\% 34$ \\
\hline Kafa içine kanama & $\% 3$ \\
\hline Kronik akciğer hastalı̆̆ı & $\% 1$ \\
\hline Ölüm & $\% 3$ \\
\hline
\end{tabular}


Gestasyon haftası 32 ve altında olan 59 hastanın \%49'unda kendiliğinden kapanma, \%48'inde tıbbi tedavi ile kapanma görüldü. Tıbbi tedaviyle kapanma olmayan ve önemli sol-sağ şantı olan iki hastada (\%3) cerrahi "ligasyona" gidildi. Gestasyon haftası 33 ve üzeri olan 41 hastanın \%78'inde kendiliğinden kapanma, \%22'sinde tıbbi tedavi ile kapanma izlendi. Gestasyon yaşı 33 hafta ve üzerinde olan hastalarda, 32 hafta ve altında olanlara göre kendiliğinden kapanma oranındaki yükseklik istatistiksel olarak anlamlıydı ( $p=0,006)$ (Tablo 2). Gestasyon yaşı azaldıkça tıbbi tedavi gereksinimi arttı.

Hastalarımız doğum ağırlıklarına göre değerlendirildiğinde \%21'i 1000 gr ve altında, \%29'u 1001-1500 gr, \%16's 15011750 gr ve \%34'ü 1750 gr'ın üzerindeydi. Kendiliğinden kapanma izlenen 61 hastanın ortalama doğum ağırlığı $1743,28 \pm 641,60 \mathrm{gr}$ iken, ibuprofen tedavisi ile kapanma izlenen 37 hastanın ortalama doğum ağırlığı 1352,84 540,62 gr olarak saptandı. Cerrahi "ligasyon" uygulanan her iki hastanın doğum ağırlığı da 950 gramdı. Doğum ağırığı azaldıkça tıbbi veya cerrahi tedavi gereksinimindeki artış istatistiksel olarak anlamlıydı $(p=0,003)$.

Surfaktan tedavisi gerektiren sıkıntılı solunum sendromuna (SSS) 100 hastanın 34'ünde rastlandı (\%34) (Tablo 1). Bu 34 hastadan 23'ü (\%67) ibuprofenle kapatma tedavisi uygulanacak düzeyde hemodinamik ve klinik olarak anlamlı PDA'ya sahipti. Patent duktus arteriyozus kapatma tedavisi alan 23 SSS'li bebeğin 22'si 32 gestasyon haftasından küçüktü (\%95). Başka bir deyişle hemodinamik ve klinik olarak anlamlı PDA saptanan 39 hastanın 30 'u (\%77) 32 hafta ve altında gestasyonel yaşa sahipti ve bu 30 olgudan 22'sinde surfaktan tedavisi gerektiren ağır SSS bulguları vardı (\%73) (Tablo 2).
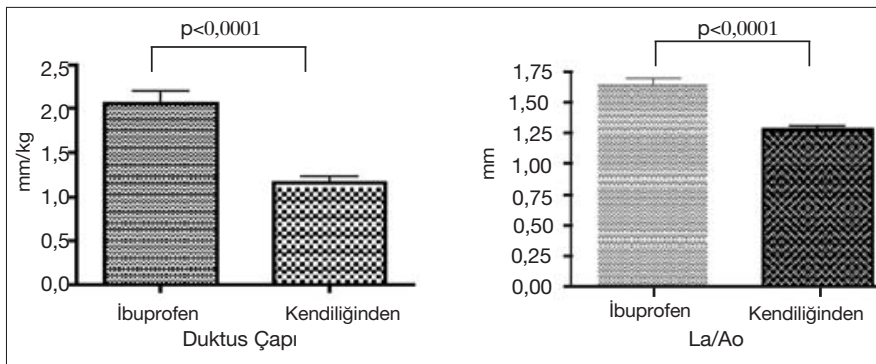

Şekil 1. Duktus çapı ve LA/Ao oranı ile kendiliğinden kapanma arasındaki ilişki
Patent duktus arteriyozus saptanan 100 hastada ortalama duktus çapı $1,51 \pm 0,83 \mathrm{~mm} / \mathrm{kg}$ ölçüldü. Hastaların duktus çapı büyüklüğü ile kendiliğinden kapanma ve tıbbi tedavi sonrası kapanma arasındaki ilişki değerlendirildiğinde kendiliğinden kapanma gözlenen 61 hastanın ortalama duktus çapları $1,16 \pm 0,51 \mathrm{~mm} / \mathrm{kg}$, ibuprofen tedavisi ile kapanma gözlenen 37 hastanın ortalama duktus çapları 2,04 $\pm 0,93 \mathrm{~mm} / \mathrm{kg}$ olarak gözlendi. Duktus çapının artmasıyla kendiliğinden kapanma oranlarındaki azalma istatistiksel açıdan anlamlıydı $(p<0,0001)$ (Şekil 1).

Patent duktus arteriyozus saptanan 100 hastanın ortalama LA/Ao oranı $1,43 \pm 0,29 \mathrm{~mm}$ bulundu. Hastaların LA/Ao oranı ile kendiliğinden kapanma ve tıbbi tedavi sonrası kapanma arasındaki ilișki değerlendirildiğinde kendiliğinden kapanma gözlenen 61 hastanın ortalama LA/Ao oranı $1,28 \pm 0,17 \mathrm{~mm}$, ibuprofen tedavisi ile kapanma gözlenen 37 hastanın ortalama LA/Ao oranı 1,65 $\pm 0,32 \mathrm{~mm}$ olarak değerlendirildi. LA/Ao oranının artmasıyla kendiliğinden kapanma oranlarındaki azalma istatistiksel açıdan anlamlıydı $(p<0,0001)$ (Şekil 1).

Tibbi tedavi alan 39 hastanın dokuzunda $(\% 25,6)$ böbrek işlev testlerinde bozulma oldu; ancak tedavi kesmeyi gerektirmedi. Tedavi bitiminde üç hastada nörolojik bulguya neden olmayan VIK $(\% 7,6)$, bir hastada surfaktan ve destek tedavisiyle kontrol edilebilen akciğerde kanama $(\% 2,5)$, bir hastada steroid tedavisi gerektiren $\mathrm{KAH}(\% 2,5)$ ve bir hastada direnajla düzelen bağırsak delinmesi $(\% 2,5)$ gelişti. Trombositopeni ve NEK gelişen hastamız olmadı. Tedavi alan 39 hastanın üçü çalışma sırasında kaybedildi. Bu hastalardan ilki doğum sonrası 8. günde, PDA tedavisinden sonra üçüncü günde surfaktan tedavisine rağmen düzelmeyen ağır SSS'ye bağlı solunum yetersizliği nedeniyle kaybedildi. İkinci bebekte ölüm nedeni postnatal beşinci günde, ibuprofen tedavisinin tamamlanmasının hemen ardından gelişen ve hızla ilerleyen pnömotorakstı. Son bebek ise ibuprofen tedavisi sırasında surfaktan ve destek tedavisiyle kontrol edilebilen akciğer kanaması gelişen ancak izlemlerinde ortaya çıkan gram negatif bakteri sepsisiyle kaybedilen bir olguydu. Öte yandan kendiliğinden kapanma izlenen üç hasta erken doğum nedeniyle izlemleri sırasında gelişen geç sepsis ve komplikasyonları nedeniyle kaybedildi. Çalışmayı 94 hasta tamamladı.

Tablo 2. Gestasyon haftasına göre kapanma oranları

\begin{tabular}{|c|c|c|c|c|c|}
\hline \multirow[b]{2}{*}{ Gestasyon haftası } & \multicolumn{3}{|c|}{ Patent duktus arteriyozus } & \multirow[b]{2}{*}{ Toplam } & \multirow[b]{2}{*}{ p } \\
\hline & $\begin{array}{l}\text { Kendiliğinden kapanan } \\
\text { n (\%) }\end{array}$ & $\begin{array}{l}\text { Ağızdan ibuprofen } \\
\text { ile kapanan } \\
n \quad(\%)\end{array}$ & $\begin{array}{l}\text { Cerrahi "ligasyonla" } \\
\text { kapanan } \\
\text { n (\%) }\end{array}$ & & \\
\hline 32 hafta ve altı & $29(49)$ & $28(48)$ & $2(3)$ & $59(100)$ & 0,006 \\
\hline 33 hafta ve üzeri & $32(78)$ & $9(22)$ & 0 & $41(100)$ & \\
\hline Toplam & 61 & 37 & 2 & 100 & \\
\hline
\end{tabular}




\section{Tartışma}

Yenidoğan yoğun bakımında ilerlemelere bağı olarak özellikle çok düşük doğum tartılı erken doğmuş bebeklerde artan yaşam oranı, bu yüksek riskli bebeklerin izleminde ortaya çıkan sorunlardan birisi olan PDA'nın tanı ve tedavisini de gündeme getirmiștir. Sağlıklı, miadında doğan bebeklerde duktusun işlevsel kapanması 2-4. günler arasındadır (9). Duktusun devam etmesi miadında doğan bebeklerde 1/2 000-1/5000 sıklıktadır ve doğuştan kalp hastalıklarının \%10'unu oluşturur $(9,10)$. Bu oran erken doğmuş bebeklerde 8/1000'e çıkmaktadır. Doğum ağırlığı 1750 gr'ın altında doğanların \%45'inde, 1200 gr'dan küçük olanların ise \%80'inde PDA görülmektedir (11). Çalıșmamıza aldığımız hastaların \%66'sının 1750 gr'ın altında, \%51'inin ise 32 hafta ve altında gestasyon yaşında olması literatürle uyumluydu. Patent duktus arteriyozus sıklığı \%16 olarak belirlendi.

Erken doğmuş bebeklerde duktus sıkığını etkileyen en önemli etmen SSS varlığıdır. Otuz gestasyon haftasından büyük bebeklerde SSS yoksa ilk 3-4 günde çoğunun duktusları kapanırken, SSS'li olanların \%10 kadarında duktus açıklığı devam eder. Otuz haftadan küçük bebeklerde ise SSS'nin duktal açıklıktaki rolü daha çoktur. Bu nedenle de kendiliğinden kapanma oranları çok düşüktür (11). Bizim çalıșmamızda kendiliğinden kapanma oranı 100 PDA tanısı konan hastada 61'di (\%61). Hemodinamik ve klinik olarak anlamlı PDA 39 hastada vardı (\%39). Bunların da 30'u (\%77) 32 hafta ve altında gestasyonel yaşa sahipti (Tablo 2). Bu 30 olgudan 22'sinde surfaktan tedavisi gerektiren SSS vardı (\%73).

Erken doğmuş bebeklerde duktal akımın önemini ve bu doğrultuda yol açacağı komplikayonları öngörebilmek amacıyla bugüne dek pek çok ölçüt tanımlanmıştır. Bu amaçla kullanılan klinik belirtiler, EKG bulguları ve göğüs röntgeninden hiç birisi kesin ve özgül bilgi vermemektedir. Doppler EKO ile saptanan duktus çapı, LA/Ao oranı, sol pulmoner arter ortalama akım hızı ve diyastol sonu akım hızı, sol ventrikül atım hacmi superior vena cava akım hızına oranı (LVO/SVC) gibi bazı ölçütler duktusun ciddiyeti konusunda çok daha güvenilir bilgi edinilmesine olanak sağlamıştır (12-14). Son çalışmalarda bu ölçütlerden en önemli ikisinin LA/Ao oranının $1,4 \mathrm{~mm}$ ve üzerinde olması ve vücut ağırlığına göre duktus çapının $1,4 \mathrm{~mm}$ ve üzerinde olması olarak belirtilmiştir (15). Bu iki ölçüte eşlik eden LVO/SVC oranının 4,5 olması ve sol pulmoner arter ortalama akım hızının $0,42 \mathrm{~m} / \mathrm{sn}$ ve üzerinde olması tanıda duyarlılığı ve özgüllüğü arttıran ek belirteçler olarak tariflenmiştir (15). Biz çalışmamızda iki temel ölçüt olan duktus çapını ve LA/Ao oranlarını kullandık. Tedavi alan grupta ortalama duktus çapı $2,04 \pm 0,93 \mathrm{~mm} / \mathrm{kg}$ ve ortalama LA/Ao oranı 1,65 $\pm 0,32 \mathrm{~mm}$ olup, kendiliğinden kapanan gruba göre belirgin derecede yüksek olması dikkat çekiciydi. İki grup arasında her iki değişken için de istatistiksel fark anlamlıydı $(p<0,0001)$.
Fetal dolaşımdan yenidoğan dönemi dolaşıma geçiş sırasında PDA'nın varlığı ve neden olduğu sol-sağ şant, erken doğmuş bebeklerde kardiyopulmoner komplikasyonlara yol açabilir (16). Bu yüzden, henüz önemli miktarda sol-sağ şant gelişmeden hastaların tedavi edilmesi gerekir $(17,18)$. Belirti veren PDA'ların tıbbi kapatılmasında indometazin uzun yıllardır kullanılmakta olan bilinen bir tedavi seçeneğidir. Ancak indometazin böbrek, sindirim sistemi ve beyin perfüzyonunda değişikliklere yol açarak çeşitli komplikasyonlara neden olabilmektedir $(4,5,17,18)$. Son yıllarda gerek damardan, gerekse de ağızdan ibuprofen ile çalışmalar yapılmakta olup, tedavi sonuçlarının iyi, yan etkilerinin daha az olduğu bildirilmektedir $(3-8,17,18)$. Su ve ark.'larının (5) yaptığı bir çalışmada, erken doğmuş yenidoğanlardaki bulgu veren PDA'ların kapatılmasında damardan kullanılan ibuprofenin \%84,4, indometazinin $\% 80,6$ oranında başarılı olduğu; ibuprofen kullanan hastalarda indometazin kullananlara göre kreatinin klirensinin ve idrar çıkışının daha fazla, serum kreatinin ve BUN değerlerinin daha düşük olduğu bildirilmiştir. Benzer şekilde ülkemizden de bildirilen pek çok çalışmada ibuprofenin böbrek yan etkilerinin önemli derecede az olduğu gösterilmiş, hatta beyin kanaması görülme sıklığını azaltarak nörolojik işlevleri koruması nedeniyle indometazine tercih edilmiştir (3,17-19). Metaanaliz verilerinde de duktusun farmakolojik tedavisinde iki ilacın etkinliği arasında istatistiksel farklılık olmadığı bildirilmiştir (6). Ancak tedavinin veriliş yolu hala tartışma konusudur. Çünkü damardan ibuprofen ülkemiz koşullarında temini zor ve oldukça pahalı bir tedavi seçeneğidir. Öte yandan ağzıdan ibuprofen kolayca temin edilebilir olması, gereken dozun çok az volümde verilebilmesi, kolay uygulanabilir olması ve ucuz olması gibi üstünlüklere sahiptir. Damardan verilen ibuprofenle aynı doz şemasının kullanıldığı bir çalışmada SSS'si olan PDA'lı erken doğmuş bebeklerde \%95,5 etkinlikle duktusun kapandığı bildirilmiştir (20). Tüm bu literatür bilgilerini kendi çalışmamızla kıyasladığımızda PDA tanılı hastalarımızın \%32'sinde tek, \%5'inde de ikinci kez ağızdan ibuprofen tedavisi ile bașarılı duktal kapanma sağlandı. Tedavi alan hastaların \%95'inde kapanma görülmesi literatürle uyumlu bulundu. Yan etkileri açısından ele alındığında ibuprofen tedavisi öncesi ve sonrası hastaların serum kreatinin, serum elektrolit ve trombosit düzeylerinde anlamlı değişiklik gözlenmezken, BUN değerlerinde saptanan hafif artış tedavi kesmeyi gerektirecek düzeyde bulunmadı. Öte yandan üç hastamızda tedavi sonrasında çekilen kraniyal USG'de nörolojik bulguya neden olmayan subependimal kanama saptandı. Ancak bu hastalar çok düşük doğum ağırlıklı ve gestasyon yaşı çok küçük bebekler olduğundan ve iki hastaya SSS tanısı konulduğundan bu durumu erken doğum komplikasyonundan ayırt etmenin güç olduğu düşünüldü. İbuprofenin koruma amaçlı kullanımıyla ilişkili artmış KAH ve pulmoner hipertansiyon sıklığı yönünde veriler sunan birkaç nadir araştırmanın aksine çalışmamızda 
hastalarımızın yalnızca \%1'inde KAH gelişmiş olup bu durum uzun süreli mekanik ventilasyonla ilişkilendirildi (21). Literatürde ağızdan ibuprofen kullanımına bağlı iki olguda kendiliğinden bağırsak delinmesi bildirilirken, çalışmamızda da benzer şekilde bağırsak delinmesi gelişen bir olguda direnajla düzelme sağlandı (22).

Sonuç olarak, erken doğmuş bebeklerde bulgu veren PDA sıklığı oldukça yüksektir. Patent duktus arteriyozusun erken tanınması, bu olgularda çeșitli organ perfüzyon bozukluklarına bağlı komplikasyonların gelişmesini önlemek açısından önemlidir. Çalışmamızın sonunda, ağızdan uygulanan ibuprofen tedavisinin yüksek etkinliği kabul edilebilir yan etkileri, düşük maliyeti ve kolay uygulanabilirliği nedeniyle erken doğmuş yenidoğanlarda duktusun kapatımasında güvenle kullanılabilecek bir uygulama olduğu düşüncesindeyiz.

\section{Kaynaklar}

1. Noori S, McCoy M, Friedlich P, et al. Failure of ductus arteriosus closure is associated with increased mortality in preterm infants. Pediatrics 2009; 123: 138-44.

2. Laughon MM, Simmons MA, Bose CL. Patency of the ductus arteriosus in the premature infant: is it pathologic? Should it be treated? Curr Opin Pediatr 2004; 16: 146-51.

3. Akısü $M$, Özyürek AR, Dorak $C$, Parlar A, Kültürsay N. Prematüre bebeklerde patent duktus arteriozus tedavisinde enteral ibuprofen ve indometazin. Çocuk Sağlığı ve Hastalıkları Dergisi 2001; 44: 56-60.

4. Pezzati M, Vangi V, Biagiotti R, Bertini G, Cianciulli D, Rubaltelli FF. Effects of indomethacin and ibuprofen on mesenteric and renal blood flow in preterm infants with patent ductus arteriosus. J Pediatr 1999; 135: 733-8.

5. Su PH, Chen JY, Su CM, Huang TC, Lee HS. Comparison of ibuprofen and indometacin therapy for patent ductus arteriosus in preterm infants. Pediatr Intern 2003; 45: 665-70.

6. Ohlsson A, Walia R, Shah SS. Ibuprofen for the treatment of patent ductus arteriosus in preterm and/or low birth weight infants. Cochrane Database Syst Rev 2010; 4: CD003481.

7. Patel J, Roberts I, Azzopardi D, Hamilton P, Edwards AD. Randomized double-blind controlled trial comparing the effects of ibuprofen with indomethacin on cerebral hemodynamics in preterm infants with patent ductus arteriosus. Pediatr Res 2000; 47: 36-42.
8. Lago P, Bettiol T, Salvadori S, et al. Safety and efficacy of ibuprofen versus indomethacin in preterm infants treated for patent ductus arteriosus: a randomized controlled trial. Eur J Pediatr 2002; 161: 202-7.

9. Yu VYH. Patent ductus arteriosus in the preterm infant. Early Hum Dev 1993; 35: 1-14.

10. Hammerman C. Patent ductus arteriosus. Clin Perinatal 1995; 22: 457-79.

11. Park MK, Troxler RG. Manifestation of cardiac problems in newborns. In: Par MK (ed). Pediatric Cardiology for Practitioners. St.Louis: Mosby, 2002: 386-8.

12. Skelton R, Evans N, Smythe J. A blinded comparison of clinical and echocardiographic evaluation of the preterm infant for patent ductus arteriosus. J Paediatr Child Health 1994; 30: 406-11.

13. Kluckow M, Evans N. Early echocardiographic prediction of symptomatic patent ductus arteriosus in preterm infants undergoing mechanical ventilation. J Pediatr 1995; 127: 774-9.

14. Suzmura H, Nitta A, Tanaka O, Arisaka O. Diastolic flow velocity of left pulmonary artery of patent ductus arteriosus in preterm infants. Pediatr Int 2001; 43: 146-51.

15. El Hajjar M, Vaksmann G, Rakza T, Kongolo G, Storme L. Severity of the ductal shunt: a comparison of different markers. Arch Dis Child Fetal Neonatal Ed 2005; 90: 419-22.

16. Takahashi $Y$, Harada K, Ishida A, Tamura M, Takada G. Left ventricular preload reserve in preterm infants with patent ductus arteriosus. Arch Dis Child 1994; 71: 118-22.

17. Kervancıoğlu M, Devecioğlu C, Köksal O. Preterm bebeklerde patent duktus arteriozus tedavisinde oral ibuprofenin etkinliğinin ve güvenirliğinin değerlendirilmesi. Dicle Tıp Dergisi 2005; 32: 140-4.

18. Tekşam Ö, Yiğit Ş, Karagöz T, Korkmaz A, Yurdakök M, Tekinalp G. Yenidoğan bebeklerde patent duktus arteriozusun tedavisinde oral ibuprofen ve intravenöz intometazin: bir retrospektif çalışma. Çocuk Sağlığı ve Hastalıkları Dergisi 2004; 47: 96-102.

19. Uraş N, Ödemiş E, Kırmemiş Ö, Tonbul A, Türkay S, Tatı MM. Preterm bebeklerde patent duktus arteriozusun enteral ibuprofen ile tedavisi. Yeni Tıp Dergisi 2007; 24: 164-7.

20. Heyman E, Morag I, Batash D, Keidar R, Baram S, Berkovitch M. Closure of patent ductus arteriosus with oral ibuprofen suspension in premature newborns. Pediatrics 2003; 112: 354.

21. Shah SS, Ohlsson A. Ibuprofen for the prevention of patent ductus arteriosus in preterm and/or low birth weight infants. Cochrane Database Syst Rev 2006; 1: CD004213.

22. Tatlı MM, Kumral A, Duman N, Demir K, Gürcü O, Özkan H. Spontan intestinal perforation after oral ibuprofen treatment of patent ductus arteriosus in two very- low-birthweight infants. Acta Pediatr 2004; 93: 999-1001. 